\title{
Comparison of HadCM3, CSIRO Mk3 and GFDL CM2.1 in Prediction the Climate Change in Taleghan River Basin
}

\author{
Arash YoosefDoost ${ }^{1, *}$, Icen YoosefDoost ${ }^{2}$, Hossein Asghari ${ }^{3}$, Mohammad Sadegh Sadeghian ${ }^{1}$ \\ ${ }^{1}$ Civil Engineering Department, Islamic Azad University Central Tehran Branch, Tehran, Iran \\ ${ }^{2}$ Water Science and Engineering Department, University of Birjand, Birjand, Iran \\ ${ }^{3}$ Environment Department, University of Tehran, Tehran, Iran \\ *Corresponding author: YoosefDoost@Gmail.com
}

\begin{abstract}
Climate change is a complex and long-term global atmospheric-oceanic phenomenon which can be influenced by natural factors such as volcanoes, solar, oceans and atmosphere activities which they have interactions between or may be as a result of human activities. Atmospheric general circulation models are developed for simulation of current climate of the earth and are able to predict the earth's future climate change. In this paper, the performance of GFDL CM2.1, CSIRO Mk3 and HadCM3 AOGCMs were assessed and evaluated in the study of the climate change effects on temperature and precipitation in Taleghan basin. The results show that HadCM3 model in comparison with CSIRO Mk3 and GFDL CM2.1 models has indicated the better performance in this region.
\end{abstract}

Keywords: Atmosphere General Circulation Models, AOGCM, CSIRO Mk3, HadCM3, Climate Change, Taleghan Region

Cite This Article: Arash YoosefDoost, Icen YoosefDoost, Hossein Asghari, and Mohammad Sadegh Sadeghian, "Comparison of HadCM3, CSIRO Mk3 and GFDL CM2.1 in Prediction the Climate Change in Taleghan River Basin.” American Journal of Civil Engineering and Architecture, vol. 6, no. 3 (2018): 93-100. doi: 10.12691/ajcea-6-3-1.

\section{Introduction}

Climate can become warmer or colder and the average of each factor of its components increases or decreases over the time, so climate change is an irreversible change in the average of weather conditions that occurs in a region. In other words, the significant statistical change is in the average of weather or its variability that continues over a long period. This change can be in the average temperature, precipitation, humidity, weather patterns, wind, solar radiation and any other weather components.

Climate change is a complex and long-term global atmospheric-oceanic phenomenon which can be influenced by natural factors such as volcanoes, solar, oceans and atmosphere activities which they have interactions between or may be as a result of human activities [1]. Some researchers considered increasing greenhouse gases as the most important factor of the the gradual increase of the earth and oceans temperatures. The earth general warming has caused two important phenomena: increasing the global temperature average and consequently increase of the sea level during the recent century. Moreover, according to regional and local scale, the climate change has a considerable influence on precipitation, evaporation, runoff and as a result in the extreme meteorology events.

From the beginning industrial revolution, the growth of industries and factories and consequently consumption of fossil fuels beside the the destruction of forests and grasslands and agricultural land use change are results of human activities and have increased the concentration of greenhouse gases particularly $\mathrm{CO}_{2}$ from $280 \mathrm{ppm}$ in 1750 to $379 \mathrm{ppm}$ in 2005. Studies show that if current trend in use of fossil fuels continues, the concentration of $\mathrm{CO}_{2}$ could reach more than $600 \mathrm{ppm}$ by the end of the twentyfirst century [2] According to the Intergovernmental report about Climate Change, the Earth's surface temperature has increased 0.3 to 0.6 degrees Celsius because of greenhouse gas emissions over the past century and it is predicted that its amount will rise to 1 to $3^{\circ} \mathrm{C}$ until 2100 .

Atmospheric General Circulation Models (AOGCMs) are developed to simulate current climate on the Earth and are able to predict future climate change on the Earth [3]. These models were introduced and used based on Norman Philips's personal investigation for the first time in 1956 when he developed a mathematical model that could realistically depict monthly and seasonal patterns in the troposphere which became the first successful climate model [4,5]. Following Phillips's work, several groups began working to create GCMs [6]. The first to combine both oceanic and atmospheric processes was developed in the late 1960s at the NOAA Geophysical Fluid Dynamics Laboratory [7]. By the early 1980s, the United States' National Center for Atmospheric Research had developed the Community Atmosphere Model; this model has been continuously refined [8]. In 1996, efforts began to model soil and vegetation types [9]. Later the Hadley Centre for 
Climate Prediction and Research's HadCM3 model coupled ocean-atmosphere elements [6]. The role of gravity waves was added in the mid-1980s. Gravity waves are required to simulate regional and global scale circulations accurately [10].

IPCC presented four major assessments in the field of climate change $\left(\mathrm{FAR}^{1}-1990, \mathrm{SAR}^{2}-1995, \mathrm{TAR}^{3}-2001\right.$ and AR4 $4^{4}$-2007) so far. Since 2007 the use of GCM models offered in AR4-2007 has considerable growth in climate change researches in comparison with other offered models in previous reports. The output of these models are accessible from Data Distribution Center (DDC) which is created in 1998 based on the proposal of Task Group on Scenarios for Climate Impact Assessment (TGICA).

\section{Materials and Methods}

\subsection{General Circulation Models}

A general circulation model (GCM) is a type of climate model. It employs a mathematical model of the general circulation of a planetary atmosphere or ocean. It uses the Naiver-Stokes equations on a rotating sphere with thermodynamic terms for various energy sources (radiation, latent heat). These equations are the basis for computer programs used to simulate the Earth's atmosphere or oceans. Atmospheric and oceanic GCMs (AGCM and OGCM) are key components along with sea ice and land-surface components [11]. GCMs and global climate models are used for weather forecasting, understanding the climate and forecasting climate change. Versions designed for decade to century time scale climate applications were originally created by Syukuro Manabe and Kirk Bryan at the Geophysical Fluid Dynamics Laboratory in Princeton, New Jersey [7]. These models are based on the integration of a variety of fluid dynamical, chemical and sometimes biological equations.

General Circulation Models are developed to simulate current climate on the Earth and are able to predict future climate change on the Earth [3]. These models were introduced and used based on Philips's personal investigation for the first time in the 1960s. Atmosphere General Circulation Models solve continuity equations for fluid dynamics in spatial and temporal discrete scales, and their structure is the same as numerical weather prediction models. The main difference is that in these models the weather predictions have been done in a shorter period of time (a few days) by defining the initial conditions precisely and their accuracy is limited to a regional with dimensions less than 150 kilometers. But the network which is defined for GCM may include some geographic latitude and longitude to simulate long-term weather [12]. In early GCM models, physical characteristics of the atmosphere at the Earth's surface were used as boundary conditions, but recently in these models atmosphere-ocean boundary conditions are used for ocean modeling and surface temperature and soil moisture are used for Earth's surface. One of the major weaknesses of these models is

\footnotetext{
${ }^{1}$ First Assessment Report

${ }^{2}$ Second Assessment Report

${ }^{3}$ Third Assessment Report

${ }^{4}$ Forth Assessment Report
}

the disability to modeling the effects of clouds on the atmosphere and inadequate accuracy to express the effects of hydrological variables such as land use. In general, GCM models have better performance to simulate and predict large-scale climate events such as assessment of enormous storms rather than expression of local and regional climate processes such as rainfall-runoff process [12].

GCM models in spatial scale, usually networked the atmosphere between 5 to 20 unequal layers. The intended network based on these models, usually has the length and width equal to 2 to 5 degree and also has a height with 6 to 15 units. These layers were near the earth surface and the layers near to surface have less distance with each other. It is evident that the fluid dynamics equations computation limits in these models have spatial and temporal dimensions. The most of GCM models for implementation requires to supercomputers. Such model requires to run time for several days to simulate changes of a region. This time is too dependent on a spatial network dimensions.

AGCMs models that are considered the atmosphere interaction and OGCMs models that are intended the oceans interaction. Usually general circulation models are included a combination of two AGCM and OGCM models. Such models are named AOGCMs.

\subsection{Special Report of Emission Scenario (SRES)}

SRES Scenarios

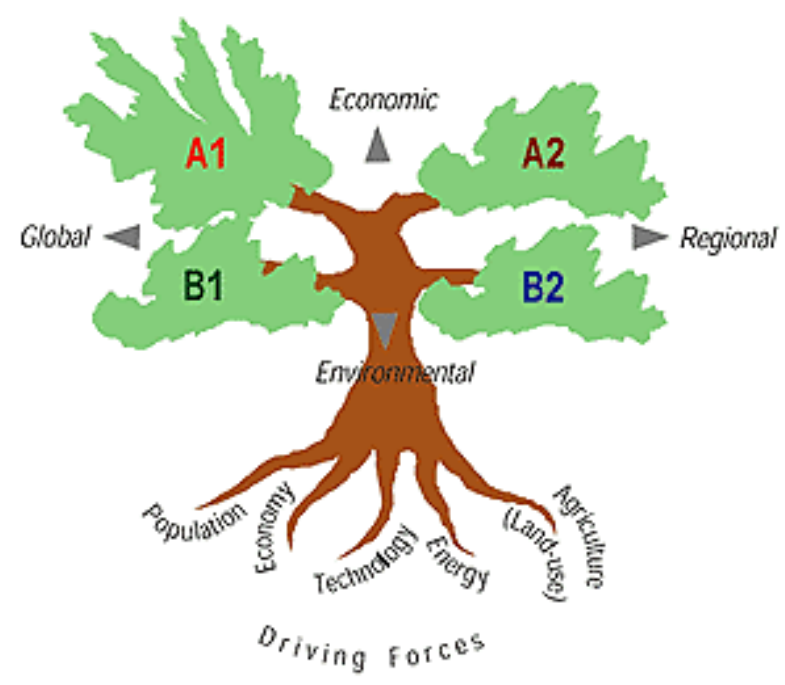

Figure 1. Four family of emission scenarios and their simulation factors [14]

IPCC provided the primary series of emission scenarios in 1992 which is called IPCC (IS92a-IS92f). In these scenarios, the amounts of greenhouse gases will increase with a fixed rate until 2100. In 1996, in order to update and replace IS92 scenarios, a series of emission scenarios called as Special Report of Emission Scenario (SRES) was published to study the climate changes. Emission scenarios were developed to explore the future developments in the global environment and provide a special reference for emission of the greenhouse gases and particulates 
in the atmosphere. SRES defines four main emission scenarios as A1, A2, B1 and B2 to describe the relation between the emission of greenhouse gases and suspended particles in the atmosphere and their effects on different parts of the world during the 21st century. These scenarios have been developed based on emission factors of greenhouse gases such as population, economy, industry, energy, agriculture and land use and each scenario offers a different situations such as social, economic, industrial and environmental [13].

Since there is no agreement on how the future will unfold, the SRES tried to sharpen the view of alternatives by assuming that individual scenarios have diverging tendencies - one emphasizes stronger economic values, the other stronger environmental values; one assumes increasing globalization, the other increasing regionalization. Combining these choices yielded four different scenario families Figure 1. This two-dimensional representation of the main SRES scenario characteristics is an oversimplification. It is shown just as an illustration. In fact, to be accurate, the space would need to be multi-dimensional, listing other scenario developments in many different social, economic, technological, environmental, and policy dimensions. The titles of the four scenario storylines and families have been kept simple: A1, A2, B1, and B2. There is no particular order among the storylines; they are listed in alphabetical and numerical order [14]:

- The A1 storyline and scenario family describes a future world of very rapid economic growth, global population that peaks in mid-century and declines thereafter, and the rapid introduction of new and more efficient technologies. Major underlying themes are convergence among regions, capacity building, and increased cultural and social interactions, with a substantial reduction in regional differences in per capita income. The A1 scenario family develops into three groups that describe alternative directions of technological change in the energy system. The three A1 groups are distinguished by their technological emphasis: fossil intensive (A1FI), non-fossil energy sources (A1T), or a balance across all sources (A1B).

- The A2 storyline and scenario family describes a very heterogeneous world. The underlying theme is self-reliance and preservation of local identities. Fertility patterns across regions converge very slowly, which results in continuously increasing global population. Economic development is primarily regionally oriented and per capita economic growth and technological change are more fragmented and slower than in other storylines.

- The B1 storyline and scenario family describes a convergent world with the same global population that peaks in mid-century and declines thereafter, as in the A1 storyline, but with rapid changes in economic structures towards a service and information economy, with reductions in material intensity, and the introduction of clean and resource-efficient technologies. The emphasis is on global solutions to economic, social, and environmental sustainability, including improved equity, but without additional climate initiatives.

- The B2 storyline and scenario family describes a world in which the emphasis is on local solutions to economic, social, and environmental sustainability. It is a world with a continuously increasing global population at a rate lower than in A2, intermediate levels of economic development, and less rapid and more diverse technological change than in the B1 and A1 storylines. While the scenario is also oriented towards environmental protection and social equity, it focuses on local and regional levels.

\subsection{Downscaling}

Due to computational limitations, analysis of general climate predictions have been doing by limited centers which are equipped with specific supercomputers for these calculations. Currently, more than 40 organizations in the world have developed different models of general circulation for the planet Earth. One of the major limitations in using the output of GCM models is having large-scale computational cells in terms of their spatial and temporal which does not have required match to hydrological models. Different methods exist to produce regional climate scenarios from climate scenarios of GCM models, which are called small scaling of these methods. In proportional method usually monthly ratios are achieved for historical series. For this purpose, it is necessary to produce scenarios of climate change for temperature and precipitation at first step. In order to calculate the climate change scenario in each model, the difference values for temperature (equation (1)) and the ratio of rainfall (equation(2)) are being calculated for long-term average in each month in future periods and basic simulated periods by the model for each cell of the computational grid [15].

$$
\begin{gathered}
\Delta T_{i}=T_{G C M}, \text { fut }, i-T_{G C M}, \text { base }, i \\
\Delta P_{i}=\frac{P_{C G M, f u t, i}}{P_{C G M, o b s, i}}
\end{gathered}
$$

In the above equations $\Delta T_{i}$ and $\Delta P_{i}$ indicates climate change scenarios of temperature and precipitation for long-term average for $\mathrm{i}$ months $(12 \leq \mathrm{i} \leq 1)$, respectively. $T_{G C M, f u t, i}$ is simulation of long-term average of temperature by the GCM for i months in future periods, $T_{G C M, b a s e, i}$ is simulation of long-term average of temperatures by GCM in the same period with observed period for i months. $P_{C G M, f u t, i}$ is simulation of long-term average of temperature by the GCM for i month in future periods, $P_{C G M, o b s, i}$ is simulation of long-term average of temperatures by GCM in the same period with observed period for i months [16].

Because of the large computational cells in GCM models, simulation of climatic fluctuations is associated with turbulence. In order to eliminate these turbulences, usually instead of direct use of GCM data in climate change calculations, the long-term periodic average of data is used, then Change Factor method is used for minimizing scale of data. In Change Factor method to make careful time series of climatic scenario in future, climate change scenarios are added or multiplied in observed values. 


$$
\begin{aligned}
& T=T_{o b s}+\Delta T \\
& P=P_{o b s} \times \Delta P
\end{aligned}
$$

In the above equations, $\mathrm{T}_{\text {obs }}$ and $\mathrm{P}_{\mathrm{obs}}$ are time series of observation temperature and precipitation in the base period, respectively. $\mathrm{T}$ and $\mathrm{P}$ are time series of climatic scenarios of temperature and precipitation in future period, $\Delta \mathrm{T}$ and $\Delta \mathrm{P}$ are climate change scenarios of minimized scale of temperature and precipitation.

\subsection{Validation Criteria and Methods}

In statistics, correlation refers to any statistically significant relationship between two variables, Pearson correlation coefficient has been developed by Karl Pearson based on an original idea of Francis Galton, which measures linear relationship between two random variables. The correlation coefficient can have values between -1 to +1 in which if the correlation be close to +1 , correlation is more and direct, and if correlation be close to -1 , correlation is more but indirect and zero mean a lack of correlation. In this study, the Pearson correlation coefficient was used to compare the results of generated data with observed one based on definition for a statistical sample with $n$ couples $\left(\mathrm{O}_{\mathrm{i}}, \mathrm{P}_{\mathrm{i}}\right)$ we have:

$$
r=\frac{\sum_{i=1}^{n}\left(O_{i}-\bar{O}\right)\left(P_{i}-\bar{P}\right)}{\sqrt{\sum_{i=1}^{n}\left(O_{i}-\bar{O}\right)^{2}} \sqrt{\sum_{i=1}^{n}\left(P_{i}-\bar{P}\right)^{2}}}
$$

The mean absolute error (MAE) is criteria to measure how much predicted results are close to desirable ones. This criterion is measurable by the following equation:

$$
\operatorname{MAE}=\frac{1}{\mathrm{n}} \sum_{\mathrm{i}=1}^{\mathrm{n}}\left|\mathrm{O}_{\mathrm{i}}-\mathrm{P}_{\mathrm{i}}\right|
$$

Root mean square deviation (RMSD) or root mean square error (RMSE) is a common measuring criterion that is calculated from the difference between the predicted values by model or estimator and the observed data. In fact, RMSD indicates the sample standard deviation from the predicted values and the observed data. These differences are called residual when calculations are estimated from samples and are called forecast error when are predicted out of sample. RMSE is an acceptable measure to compare the prediction errors of a special variable that is measurable by the following equation:

$$
\operatorname{RMSE}=\frac{\sqrt{\sum_{\mathrm{i}=1}^{\mathrm{n}}\left(\mathrm{O}_{\mathrm{i}}-\mathrm{P}_{\mathrm{i}}\right)^{2}}}{\mathrm{n}}
$$

In all equations $\mathrm{O}_{\mathrm{i}}$ is the observed data, $\mathrm{Pi}$ is estimated value, $\overline{\mathrm{O}}$ is the average of observational data, $\overline{\mathrm{P}}$ is the average of estimated data and $n$ is the number of data.

\subsection{Case Study}

Based on the water master plan of Iran, the SefidRood River basin is consist of 17 sub-basins. The Shahrood (Taleghan) cachment with $960 \mathrm{Km}^{2}$ area is located in east of SefidRood basin. It is located in central part of Alborz Mountains and the most important feature, is its high altitude and steep slope. The average elevation of basin is 2665 meters above sea level and its maximum and minimum height is 4300 and 1390 meters, respectively. Also 50 percent of Taleghan catchment has more than $40 \%$ slope and its general direction is east-west. Distribution of precipitation varies between 250 and $1000 \mathrm{~mm}$ per year and annual average rainfall of the entire basin is about 600 $\mathrm{mm}$. The Shahrood (Taleghan) River length is $85 \mathrm{Km}$ and it's flood season mostly is in spring [17].

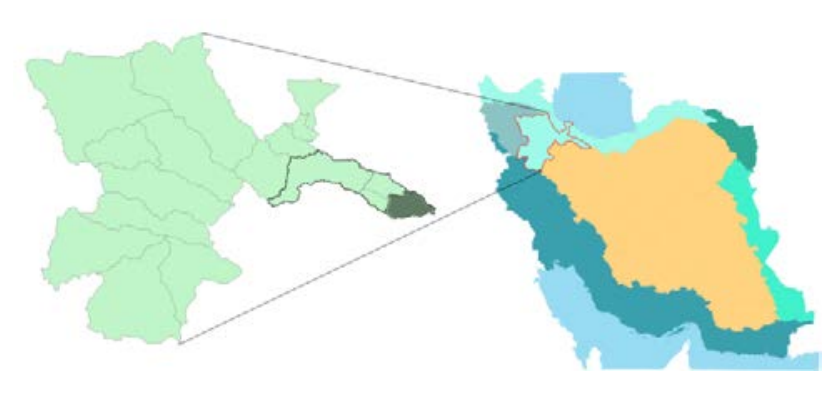

Figure 2. The Taleghan basin

According to the chart 1 the average of annual rainfall is $600 \mathrm{~mm}$ in the basin and the months with the most amount of precipitation are April and May. For all stations, winter months experience more than 45 millimeters of rainfall. Joostan, Gateh deh and Galidar precipitation stations have high impact on average rainfall and consequently on catchment runoff according to its rate of precipitation and catchment height.

However, according to information of Zidasht station, the average temperature in this area is the $7.8^{\circ} \mathrm{C}$. The absolute maximum temperature is $37^{\circ} \mathrm{C}$ in July and minimum temperature is $-18^{\circ} \mathrm{C}$ which is measured in March.

As chart 2 shows, for temperature variable monthly data of Zidasht with elevation of 2000 meters due to its lowest difference elevation with the average elevation of the basin $(372 ' 2 \mathrm{~m})$, this station was considered as the basis and according to elevation difference between Ziadasht station and the average elevation of the upstream basin of Taleghan, with use of a temperature gradient and height, temperature data related average basin would be calculated.

\subsection{Method of Investigation}

Considering to the time constraints of available data for rainfall, temperature and runoff in a common period in selected stations and the need for long period for using rainfall-runoff model, 1968-2008 period was chosen. Rainfall, temperature and monthly runoff data of selected basin stations were corrected and completed. To obtain the average rainfall of the basin, weighted average of the selected stations were used. Therefore, for each station weighted average was taken into based on its elevation and area and average level and total area of the basin. 


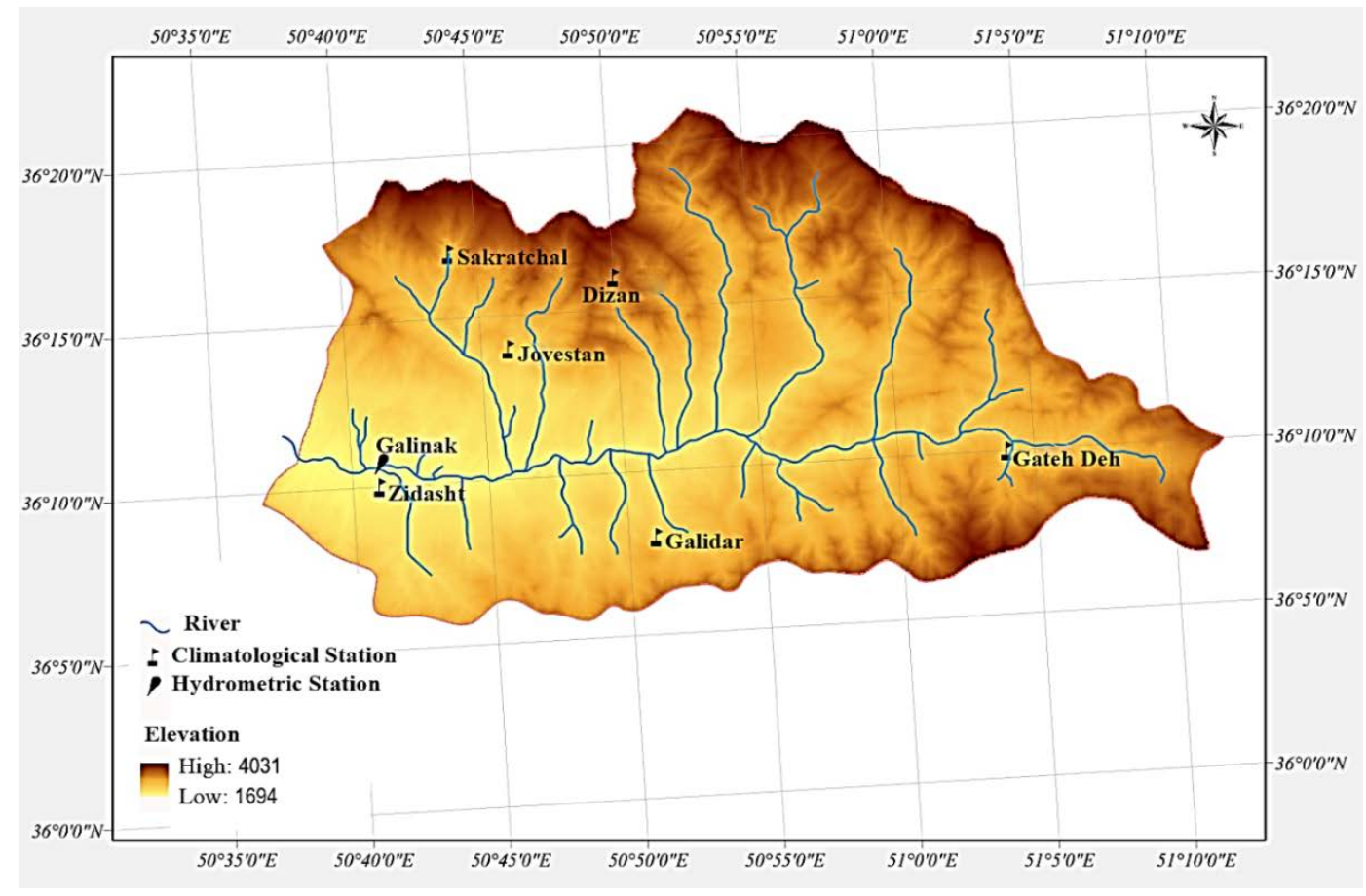

Figure 3. The climatological and hydrometric stations in upstream basin of Taleghan

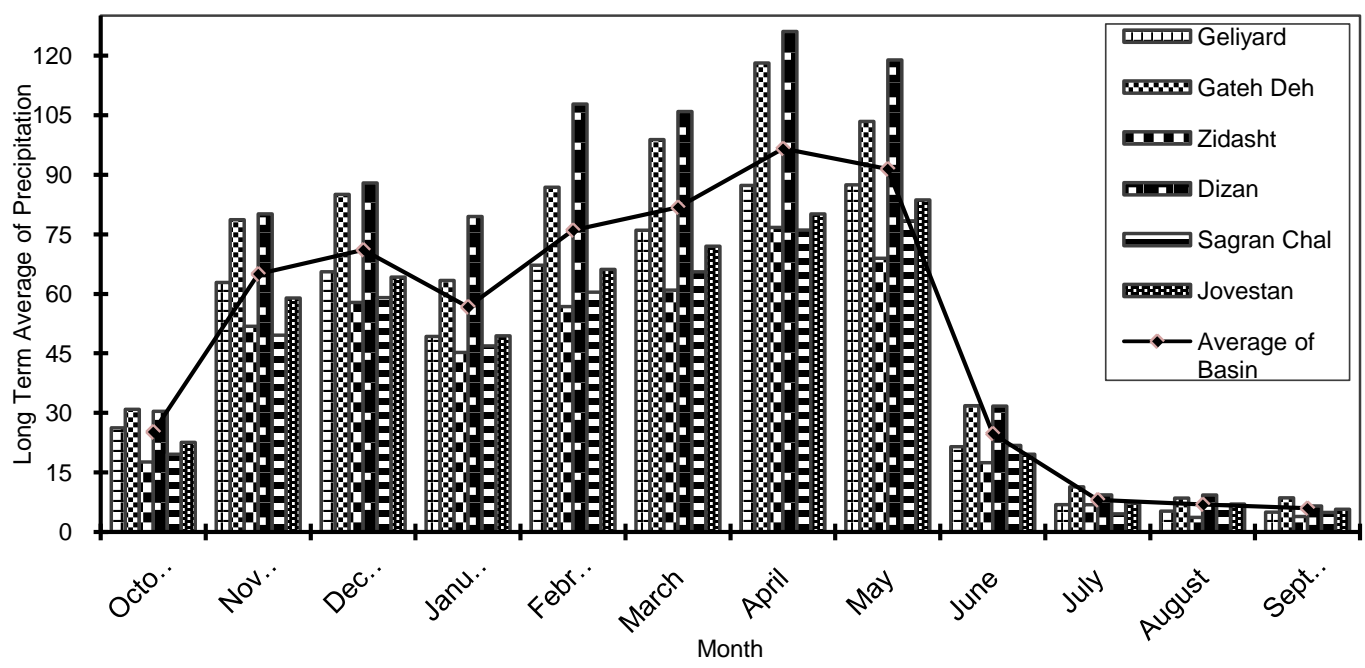

Chart 1. The long-term average of monthly rainfall in each station

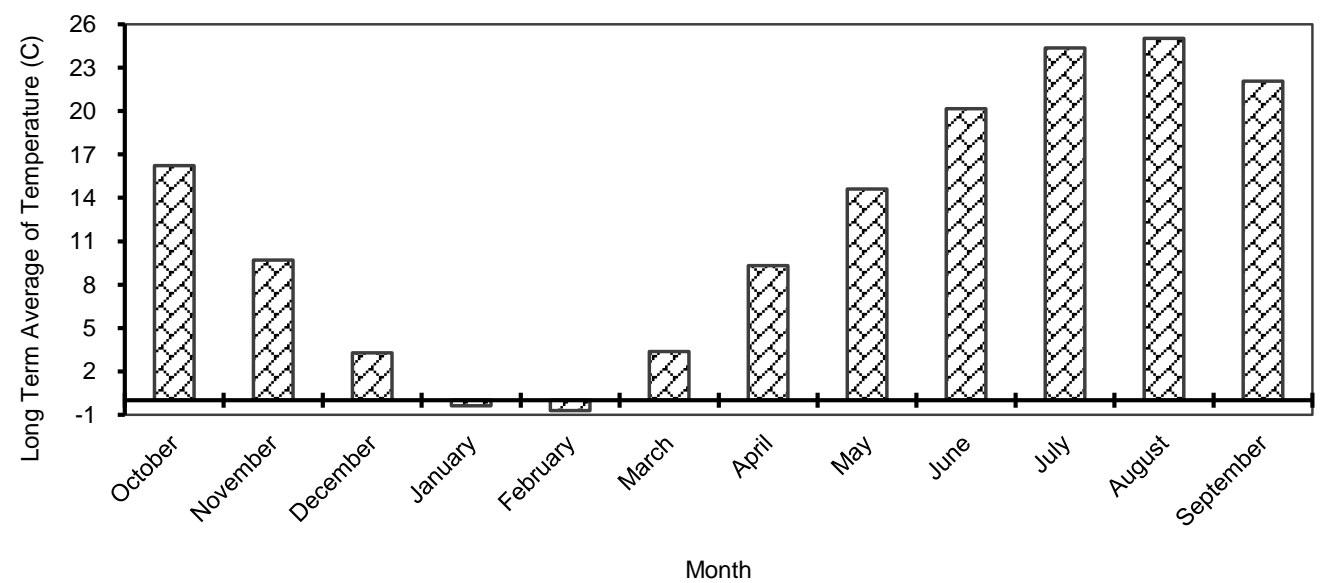


General specifications of AOGCMs, IPCC fourth Assessment Report and relevant scenarios that were used in this study are shown in Table 1.

In order to evaluate the performance of GCM models, the observed levels of greenhouse gases by 2000 is used as inputs of models in order to simulate past climatic variables in the form of monthly time series in this period [18]. Then, for simulating the status of these variables in future periods, it is necessary to introduce the state of emissions of greenhouse gases (IS92 or SRES scenarios) for these models. Since the A2 emission scenario shows stricter conditions for the status of greenhouse gas emissions and it's conditions is closer to the current situations of this region, it was selected as the emission scenario of AOGCMs for simulating the regional climate variables.

Finally, monthly precipitation and temperature data selected from GCM models that contain the time-series variables of computational cells surrounding the Earth's climate, were taken from CCCSN, and monthly precipitation and temperature data for the base period related to computational cell which was located in selected stations of the basin (original cells) were extracted, after that, 40-years average of monthly precipitation and temperature of the cells were determined. Finally, the predicted data was compared with 40 years average of monthly observed precipitation and temperature of basin in base period and the preformance of models was evaluated with validation criteria.

\section{Results and Analysis}

Chart 3 and Chart 4 indicates the comparison of 40 years monthly average of models predictions and observed precipitation and temperature in the base period.

In order to evaluate the performance of models in simulation the regional climate variables coefficient of determination $\left(R^{2}\right)$, Root mean square error (RMSE) and mean absolute error (MAE) were used. Table 3 shows the performance of AOGCM models in simulation the average of temperature and precipitation in comparison with the observational data of basin.

Table 1. The specifications of stations in the upstream basin of Taleghan

\begin{tabular}{|c|c|c|c|c|c|}
\hline Station Name & Type & Longitude & Latitude & $\begin{array}{c}\text { Station height } \\
\text { (meters above sea level) }\end{array}$ & Period of available dada \\
\hline Geliyard & Pluviometry & $50^{\circ}: 51^{\prime}$ & $36^{\circ}: 08^{\prime}$ & 2150 & $1966-2008$ \\
\hline Gateh Deh & Pluviometry & $51^{\circ}: 04^{\prime}$ & $36^{\circ}: 10^{\prime}$ & 2600 & $1966-2011$ \\
\hline Zidasht & Climatology & $51^{\circ}: 18^{\prime}$ & $31^{\circ}: 45^{\prime}$ & 2000 & $1969-2011$ \\
\hline Dizan & Pluviometry & $50^{\circ}: 50^{\prime}$ & $36^{\circ}: 16^{\prime}$ & 3200 & $1967-2011$ \\
\hline Sagran Chal & Pluviometry & $50^{\circ}: 44^{\prime}$ & $36^{\circ}: 17^{\prime}$ & 2200 & $1966-2011$ \\
\hline Jovestan & Pluviometry & $50^{\circ}: 41^{\prime}$ & $36^{\circ}: 10^{\prime}$ & 1850 & $1966-2011$ \\
\hline Galinak & Hydrometry & $50^{\circ}: 40^{\prime}$ & $36^{\circ}: 10^{\prime}$ & 1783 & $1958-2011$ \\
\hline
\end{tabular}

Table 2. Specifications of AOGCMs that was used in this study In DDC related to the IPCC fourth Assessment Report

\begin{tabular}{|c|c|c|c|c|}
\hline Model & Founder & Simulation scenarios & Atmospheric separation power & Reference \\
\hline HadCM3 & UKMO (UK) & A1FI, A2, B1 & $2 / 5^{\circ} * 3 / 75^{\circ}$ & Pope et al. (2000) [20] \\
\hline CSIRO Mk3 & ABM (Australia) & $\mathrm{A} 2, \mathrm{~B} 1$ & $1 / 875^{\circ *} 1 / 875^{\circ}$ & Gordon et al. (2002) [21] \\
\hline GFDL CM2.1 & NOAA/GFDL (USA) & A1FI, A2, B1 & $2 / 00^{\circ} * 2 / 50^{\circ}$ & Delworth et al. (2006) [20] \\
\hline
\end{tabular}

Table 3. Validation criteria of AOGCM models in predicting temperature and precipitation

\begin{tabular}{|c|c|c|c|c|c|c|}
\hline \multirow{2}{*}{ Model } & \multicolumn{3}{|c|}{ Temprature } & \multicolumn{3}{|c|}{ Precipitation } \\
\hline & $\mathrm{R}^{2}(\%)$ & RMSE & MAE & $\mathrm{R}^{2}(\%)$ & RMSE & MAE \\
\hline CSIRO Mk3 & 76 & 7.5 & 11.32 & 98 & 3.34 & 2.98 \\
\hline GFDL CM2.1 & 89 & 12.49 & 33.11 & 98 & 3.74 & -4.61 \\
\hline HadCM3 & 89 & 4.69 & -2.29 & 99 & 1.14 & 1.92 \\
\hline
\end{tabular}

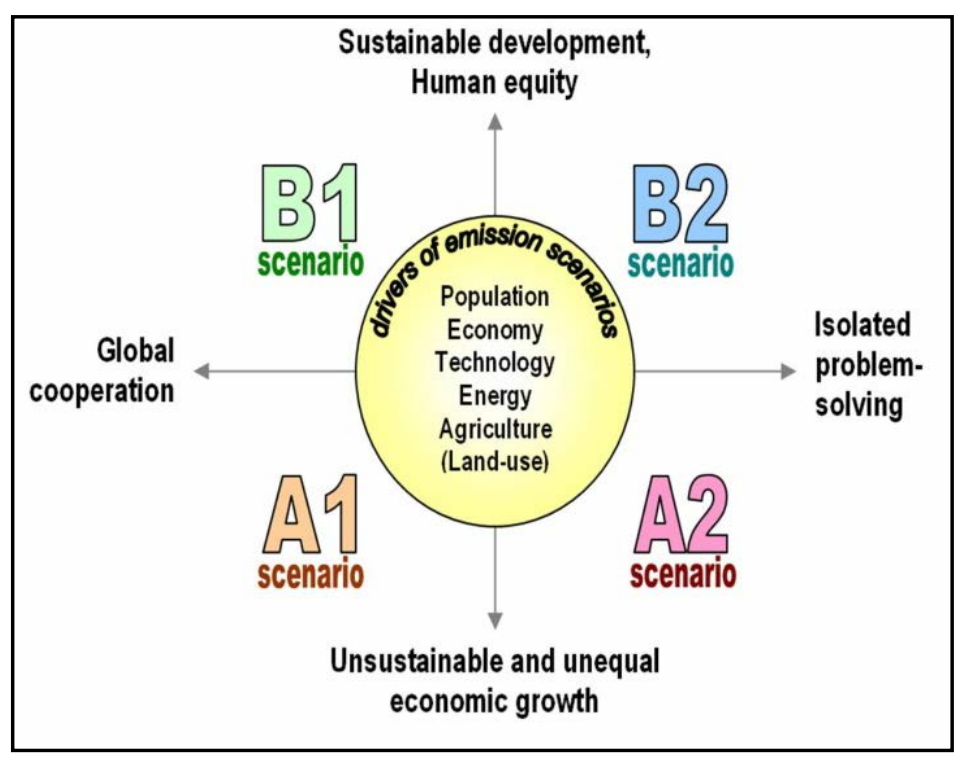

Figure 4. Descission factors in selecting the best emission scenario [19] 


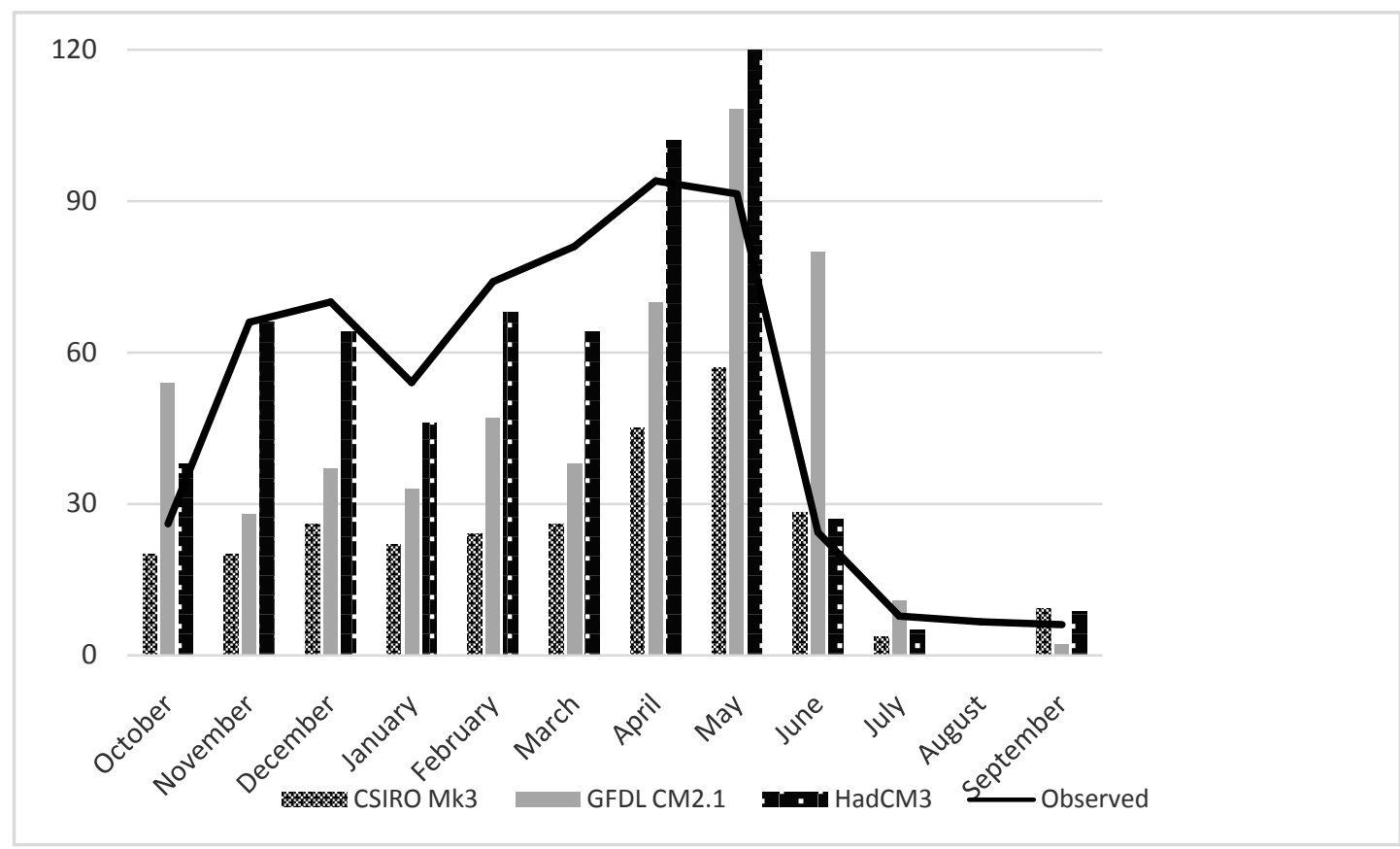

Chart 3. Comparison of 40 years monthly average of the observational and predicted precipitation

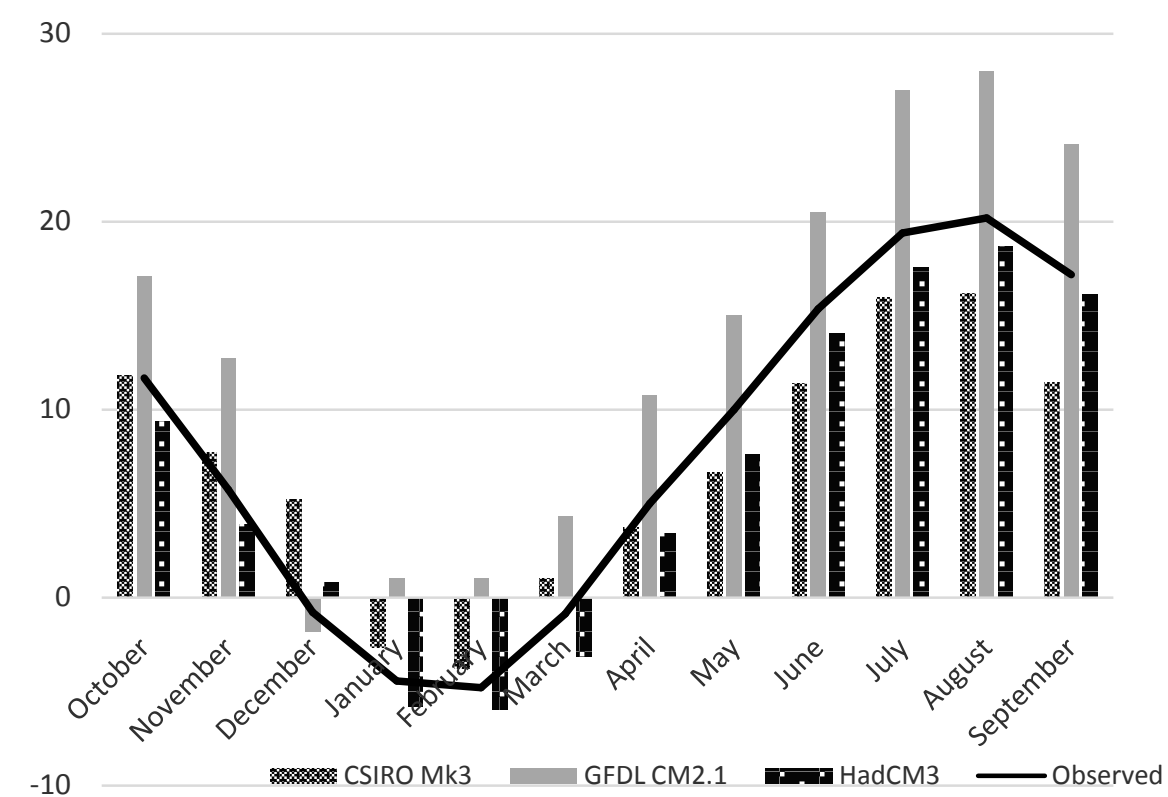

Chart 4. Comparison of 40 years monthly average of the observational and predicted temperature

\section{Conclusion}

According to the validation criteria, the simulation of the temperature shows a high $R^{2}$ for all models and low RMSE and MAE. Although the $R^{2}$ for GFDL CM2.1 and HadCM3 is high and almost the same, the comparison of RMSE and MAE in simulation of precipitation and temperature shows better results for HadCM3. Additionally, in comparison of HadCM3 with CSIRO Mk3, the HadCM3 validation criteria for precipitation is better. Additionally in prediction of temperature HadCM3 shows lower RMSE and MAE than GFDL CM2.1 which indicates less errors in this model predictions and the better performance of HadCM3.

Analysis of comparison of monthly average of the observational and predicted precipitation in charts shows that all models predicted zero precipitating in August while its actual average is more than $6 \mathrm{~mm}$. Additionally, CSIRO Mk3 predicts the precipitation in the lowest amount in all months except September, June and October which is significantly lower than observations and other models predictions. In fact, this model shows acceptable predictions only in October and July and in other situations the predictions have significant distance from the basin long-term average.

On the other hand, the GFDL CM2.1 shows significantly higher amount of precipitation predictions in October, May and June while in the other months the predictions are considerably lower than observed data. So the predicted precipitation amount by both of GFDL CM2.1 and CSIRO Mk3 is so low that has significant distance from the basin long-term average in general. This issue is so considerable 
about CSIRO Mk3 that can be stated that its predictions is not desirable in general.

Finally it seems HadCM3 predicts higher amounts for precipitation in October, April and May and what is predicted in May is considerably higher in comparison with the basin average. However, the predictions in other months are closer than other studied models to the actual amounts. So it seems that HadCM3 shows better performance in comparison with other studied models.

Analysis of comparison of monthly average of the observational and predicted temperature in charts shows that although the general trend of predictions of all studied models shows good conformity with observations in most cases, the amount of predictions of GFDL CM2.1 in almost all situations are so high that cannot be consider as desirable predictions. On the other hand CSIRO Mk3 predicts the temperature much higher than actual in December and almost the same of actual amount in October, November and April. Finally although HadCM3 predictions are less than actual amounts in almost all situations especially in January, February and March, its predictions are closer to the actual amounts in comparison with other models and it seems that the predictions of HadCM3 has the most conformity with observations.

In conclusion it can be stated that HadCM3 shows better performance according both validation criteria and predicting the general trends of observational data. So it seems that HadCM3 temperature and precipitation predictions are more reliable in this case study.

\section{References}

[1] J. Buchdahl, A review of contemporary and prehistoric global climate change. Chester Street, Manchester M1 5GD: Manchester Metropolitan University, 1999.

[2] IPCC 2007a, Climate Change: The Physical Science Basis. Contribution of Working Group I to the Fourth Assessment Report of the Intergovernmental Panel on Climate Change. Cambridge University Press, Cambridge.

[3] C. Xu, "From GCMs to river flow: a review of downscaling methods and hydrologic modelling approaches," Prog. Phys. Geogr., vol. 23, no. 2, pp. 229-249, Jun. 1999.

[4] P. Norman A., "The general circulation of the atmosphere: A numerical experiment,” Q. J. R. Meteorol. Soc., vol. 82, no. 352, pp. 123-164, Apr. 1956.

[5] J. D. Cox, Storm watchers: the turbulent history of weather prediction from Franklin's kite to El Niña John Wiley, 2002.

[6] P. Lynch, "The Emergence of Numerical Weather Prediction," in The ENIAC Integrations, Cambridge University Press, UK., 2006.
[7] N. O. and A. A. US Department of Commerce, "The First Climate Model,” NOAA, 2007. [Online]. Available:

https://celebrating200years.noaa.gov/breakthroughs/climate_mode 1/welcome.html. [Accessed: 23-Sep-2017].

[8] W. D. Collins, Description of the NCAR Community Atmosphere Model (CAM 3.0). University Corporation for Atmospheric Research, 2004.

[9] Y. Xue, M. J. Fennessy, and P. J. Sellers, "Impact of vegetation properties on U.S. summer weather prediction,” J. Geophys. Res. Atmos., vol. 101, no. D3, pp. 7419-7430, Mar. 1996.

[10] K. McGuffie and A. Henderson-Sellers, A climate modelling primer. J. Wiley, 2005.

[11] R. Heikes and D. A. Randall, "General Circulation Model," Colorado State University. [Online]. Available: https://en.wikipedia.org/wiki/General_circulation_model. [Accessed: 23-Sep-2017].

[12] S. Karamooz, M., Araghy nejad, Advanced Hydrology. Tehran: Amirkabir Technology University Press, 2005.

[13] 2000 IPCC, Emissions Scenarios. Cambridge University Press, UK.

[14] “IPCC - Intergovernmental Panel on Climate Change,” IPCC.ch. [Online]. Available:

http://www.ipcc.ch/ipccreports/tar/wg3/index.php?idp=81. [Accessed: 22-Sep-2017].

[15] P. D. JONES and M. HULME, "CALCULATING REGIONAL CLIMATIC TIME SERIES FOR TEMPERATURE AND PRECIPITATION: METHODS AND ILLUSTRATIONS,” Int. J. Climatol., vol. 16, no. 4, pp. 361-377, Apr. 1996.

[16] A. Yoosefdoost, M. Raisi, and P. Esmaeli, "Comparison of the Performance of HadCM3, GFDL CM 2.1 and CGCM3 Models in Estimating the Climate Change Effects on Rainfall and Temperature in Taleghan Basin Under SRES A2 Scenario,” in The International Congress on Enviroment, 2015.

[17] A. YoosefDoost, M. Sadegh Sadeghian, M. Ali Node Farahani, and A. Rasekhi, "Comparison between Performance of Statistical and Low Cost ARIMA Model with GFDL, CM2.1 and CGM 3 Atmosphere-Ocean General Circulation Models in Assessment of the Effects of Climate Change on Temperature and Precipitation in Taleghan Basin,” Am. J. Water Resour., vol. 5, no. 4, pp. 92-99, Sep. 2017.

[18] J. D. Lambert, K. P. McFarland, C. C. Rimmer, S. D. Faccio, and J. L. Atwood, “A Practical Model of Bicknell'S Thrush Distribution in the Northeastern United States,” The Wilson Bulletin, vol. 117, no. 1. pp. 1-11, 02-Mar-2005.

[19] "Potential Impacts of Climate Change on Biodiversity - SERVIR." [Online]. Available: http://www.servir.net/haiti-earthquake2010/25-noticias/ultimas-noticias/373-potential-impacts-ofclimate-change-on-biodiversity.html. [Accessed: 25-Sep-2017]

[20] V. D. Pope, M. L. Gallani, P. R. Rowntree, and R. A. Stratton, "The impact of new physical parametrizations in the Hadley Centre climate model: HadAM3,” Clim. Dyn., vol. 16, no. 2-3, pp. 123-146, Feb. 2000

[21] K. H. Gordon, M. Perez, and T. E. Joiner, "The impact of racial stereotypes on eating disorder recognition," Int. J. Eat. Disord., vol. 32, no. 2, pp. 219-224, Sep. 2002. 